\title{
Diabetes Case Burden at Central Regional Referral Hospital, Gelephu, Bhutan; A Retrospective Study
}

\section{VISHAL CHHETRI ${ }^{1}$ iD, HARI PRASAD POKHREL*2 iD, LUNGTEN ZANGMO³, LAIGDEN DZED4id}

BACKGROUND: Diabetes is a metabolic disorder affecting millions of people globally. The incidence of type 2 diabetes is increasing rapidly in Bhutan. Anecdotal evidences show poor compliance and loss to follow up among the Bhutanese population living with diabetes. This study was conducted to understand the case load, age and gender distribution and compliance to follow up among diabetic patients registered at Central Regional Referral Hospital, Gelephu, Bhutan.

MATERIALS \& METHOD: All the patients diagnosed and registered with Diabetic Clinic between $1^{\text {st } J a n u a r y ~} 2014$ to $31^{\text {st }}$ December 2018 were included in the study.

RESULTS: There was a sharp increase in number of registered diabetic patients from 641 cases in 2014 to 1590 cases in 2018 . A total of 949 new cases were diagnosed and registered during the study period of which $5 \mathbf{2} \%$ were women. The overall diabetes prevalence under Gelephu CRRH catchment area is found to be $2.91 \%$ with lowest at Chhudzom (1.01\%) and highest in Samtenling Gewog (3.18\%). Lost to follow up among new cases for past four years was found to be 3.96\%, 5.0\%, 6.47\% and 5.85\% from 2015 to 2018 respectively.

CONCLUSION: The ageing population and sedentary lifestyle has contributed to the sharp escalation of type 2 diabetes cases in Gelephu. The hospital recorded total of 1590 cases in 2018 which is a two-fold increase in case load within a span of five years. The current analysis found that loss to follow up was 3.96\%, 5.0\%, 6.47\% and 5.85\% from 2015 to 2018 respectively among new cases of diabetes registered with the hospital.

KEYWORDS: Bhutan, Sedentary Lifestyle, Non-Communicable Disease

\section{INTRODUCTION}

Diabetes mellitus is a chronic metabolic disorder characterized by hyperglycemia and the late development of vascular and neuropathic complications. Regardless of its cause, the disease is associated with a deficiency in insulin secretion, impaired action or both. ${ }^{1}$ The individuals with family history of diabetes, obesity ${ }^{2}$, hyperlipidemia, hypertension, sedentary lifestyle and aging population ${ }^{3}$ are at risk of developing type 2 diabetes mellitus (T2DM). ${ }^{4,5}$ The prevalence of diabetes in rural populations and in men is estimated to be higher than that of urban population and women. ${ }^{2}$

Morbidity and mortality due to non-communicable diseases (NCD); such as diabetes, hypertension, alcohol liver disease (ALD), heart disease and cataract is a global concern and Bhutan is no exception (Bhutan, Annual Health Bulletin, 2017). The prevalence of T2DM for all the age-groups globally was estimated to be $2.8 \%$ in the year 2000 and would increase to $4.4 \%$ in 2030 , increasing the number from 171 million in 2000 to 366 million in 2030. This increase is mostly expected in South Asia ${ }^{6}$ which will result in an increased economic burden. ${ }^{7}$ India had the highest number of people with diabetes mellitus (31.7 million) followed by China (20.8 million) in the year $2000 .^{2}$

The three group of oral hypoglycemic agents used are insulin secretagogue (sulphonyuria), insulin sensitizer (metformin) and $\alpha$-glucosidase inhibitor. Metformin is used as first-line treatment for $\mathrm{T}_{2} \mathrm{DM}$ as a monotherapy; recommended by American Diabetes Association (ADA) with addition of second-line treatments on the basis of considerations of efficacy, risk of hypoglycemia, weight, side-effects, and costs. ${ }^{8}$ Despite an increasing knowledge of the risk factors for T2DM and evidence for successful prevention programmes, the incidence of the disease continues to grow globally. Therefore, early detection through mass health check-up, education and encouraging healthy 
habits with the availability of safe and effective therapies will definitely reduce morbidity and mortality due to any NCD, including diabetes.

In Bhutan around 33,00o people are estimated to be suffering from diabetes and the nationwide STEP-wise surveillance (STEPS) survey conducted in 2014 found $6.4 \%$ had raised fasting blood glucose. ${ }^{5}$ The annual health bulletin 2017 reported that the incidence rate is relatively high with 82 cases per 10000 populations and the number of T2DM cases increased from 4097 in 2012 to 12120 in 2016, an increase by three folds (http://www.health.gov.bt/). Apart from T2DM, other non-communicable diseases in Bhutan ${ }^{5,9}$ have significantly increased and Central Regional Referral Hospital, Gelephu (CRRH) records the second highest number of diabetes cases in Bhutan.

A country-wide review of diabetes care in Bhutan conducted by Zam et al. in $2015^{9}$ excluded Regional Referral Hospitals in their study and the annual health bulletin published by the Ministry of Health does not present a comprehensive report on diabetes cases. On the other-hand, the study mentioned that almost onethird of DM patients were lost to follow-up (LTFU). Thus, this study is deemed necessary to present the increasing number of diabetic patients visiting the hospital, understand their age and gender distribution and loss to follow up. The study will also facilitate in planning and procurement of reagents and test kits, and medicines.

\section{MATERIALS AND METHOD}

Study Design: This was a retrospective study. Using census approach, all the diabetic patients registered with the diabetic clinic of Central Regional Referral Hospital, from $1^{\text {st }}$ January 2014 to $31^{\text {st }}$ December 2018 were included in the study.

Study setting and Laboratory Diagnosis: All patients visiting hospital with clinical symptoms presenting diabetes are screened for diabetes by measuring random blood sugar (RBS). The venous blood samples are collected using fluoride anticoagulant vaccumtainer and tested within 2-3 hours of collection. ${ }^{10}$ The normal reference range for RBS is assigned at $>200 \mathrm{mg} / \mathrm{dl} .{ }^{9}$ Further, fasting plasma glucose (FPG) and two hours post prandial plasma glucose (PPPG) is measured for confirmation of $\mathrm{T}_{2} \mathrm{DM}$. The set reference value of $\geq 126$ $\mathrm{mg} / \mathrm{dl}$ in FPG and two hours PPPG $\geq 200 \mathrm{mg} / \mathrm{dl}$ is set up for diagnosis of diabetes. ${ }^{9,11}$

Registration and recording: The diabetic clinic of the hospital registers all diabetic patients and assigns a unique identification number, either as old case or new case (Old case: Those diabetes patients already diagnosed and registered with the diabetic clinic of CRRH or other hospitals and have been allotted with a D-number. New case: Those patients initially diagnosed as $\mathrm{T}_{2} \mathrm{DM}$ is through two fasting plasma glucose (FPG) measurements, (both of which must be $\geq 126 \mathrm{mg} / \mathrm{dl}$ ) and two hours post prandial plasma glucose (PPPG) $\geq 200$ $\mathrm{mg} / \mathrm{dl})$.

Treatment and Advice: Diabetic patients are advised on lifestyle modification and importance of physical activity and dietary control. They are prescribed oral drugs like metformin, glipezide and insulin, in the form of human (soluble) insulin, human zinc suspension and human mixtard (neutral isophane). ${ }^{5}$ Since diabetes is associated with other co-morbidities such as hypertension, they are managed accordingly.

Follow up: Diabetes patients are expected to visit diabetic clinic for follow-up once in a month as per the national standard of Managing Diabetes Mellitus: Guide for health workers (2007), Department of Medical Services, Ministry of Health. Although there are no formal definitions to final outcome of diabetic patients; it may be limited to; alive and retained in care, lost-to-follow-up (LTFU) and died. A patient is considered LTFU if the patient did not visit the diabetic clinic even once within a year of diagnosis and registration with the diabetic clinic.

Data Analysis: The data were collected from Diabetic clinic, CRRH and validated with the medical records section of the hospital. Data entry was done using Microsoft excel and analyzed using SPSS. Descriptive information is presented as frequency and percent. Chi square test was used to assess the association between gender and different age groups considering a p-value of $<0.05$ as statistically significant. The annual diabetes detection rate was calculated based on the total annual random blood sugar tested by laboratory and total new cases detected annually.

Ethical Clearance: Ethical clearance was granted by 
Research Ethics Board of Health (REBH), Ministry of Health, Bhutan vide letter no: Ref. No. REBH/Approval/2019/017 dated 09/05/ 2019.

\section{RESULTS}

The number of diabetes patients registered with diabetic clinic, CRRH has increased from 641 old cases in 2014 to 1590 in 2018. During the study period (20142018), a total of 949 new diabetes mellitus cases were recorded in diabetic clinic CRRH [figure 1 (a)], of which $52 \%$ were women [figure 1 (b)]. More than $59.51 \%$ of new $\mathrm{T}_{2} \mathrm{DM}$ cases detected were of age group $\geq 50$ years old and it was found to be statistically significant $(\mathrm{p}<0.05)$ [figure $2(\mathrm{a})$ ].

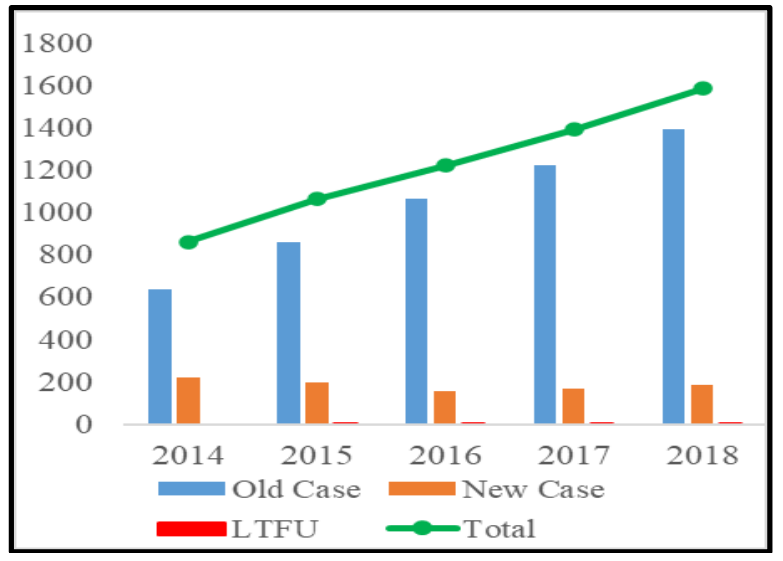

Figure 1 (a). Annual total T2DM cases detected in CRRH, Gelephu from 2014-2018 and Loss to follow-up (LTFU)

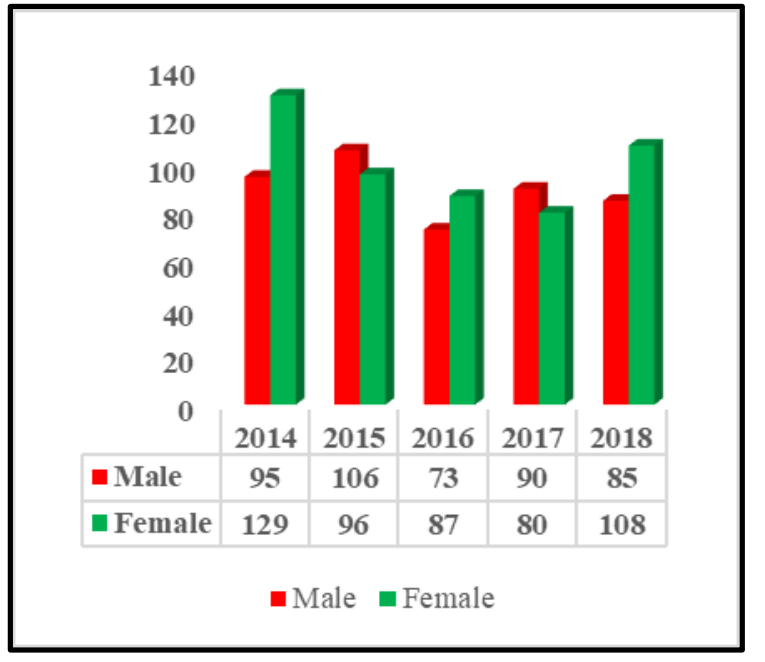

Figure 1 (b). Annual total T2DM cases detected in CRRH, Gelephu from 2014-2018 and Loss to follow-up (LTFU)
The annual detection rate was estimated to be at $\mathbf{2 . 2 2} \%$ and $1.45 \%$ in 2015 and 2018, respectively [figure 2 (b)]. The result of LTFU for past four years shows only $3.96 \%$, $5.0 \%, 6.47 \%$ and $5.85 \%$ of new diabetes cases were lost to follow-up in 2015 to 2018 , respectively.

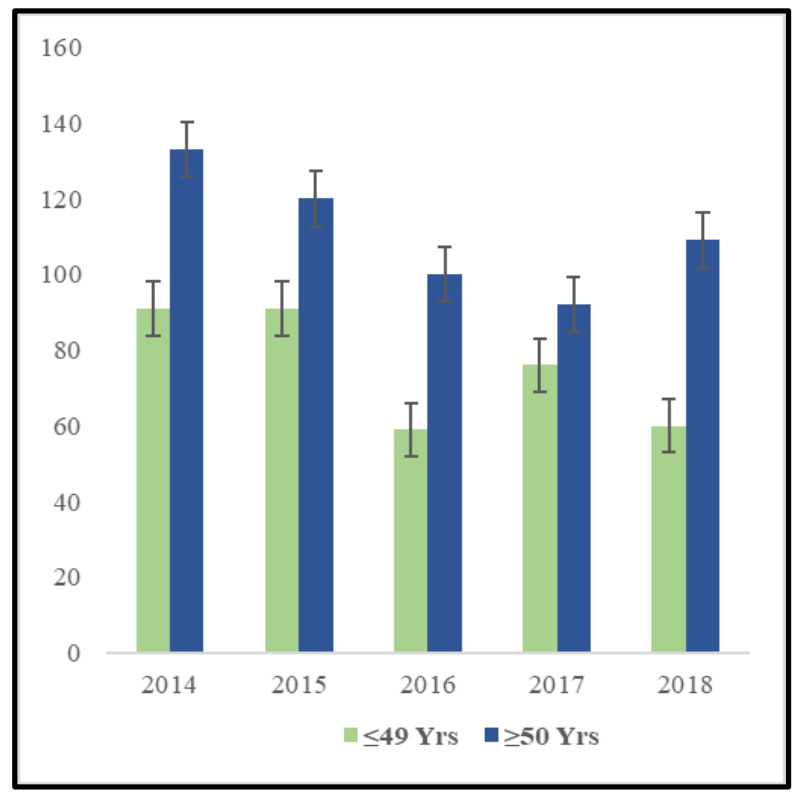

Figure 2 (a). Age group distribution of new T2DM cases detected in CRRH (2014-2018)

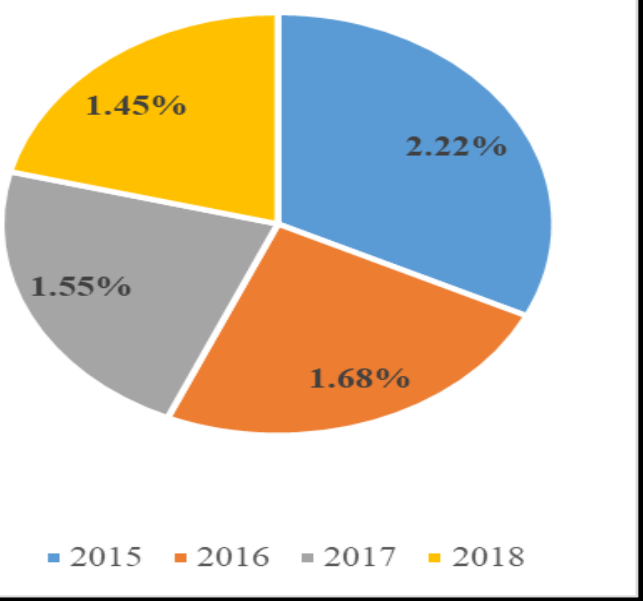

Figure 2 (b). Annual T2DM detection rate at CRRH from 2014 to 2018

\section{DISCUSSION}

The number of diabetes cases has increased by more than two folds from 641 cases in 2014 to 1590 cases in 
2018, with 949 new cases being detected within the study period. Similarly, the incidence of diabetic patients being referred from neighbouring districts increased from 1042 in 2015 to 1535 in 2018 (figure 3). This adds up significant work load to the hospital. Gelephu hospital examines the second highest number of OPD cases in the country. ${ }^{12}$ The sharp escalation of T2DM has been observed in South East Asian region. ${ }^{13}$ $\mathrm{T}_{2} \mathrm{DM}$ is mostly associated with change in lifestyle due to urbanization. Co-incidentally Gelephu has turned to Class A-urban town in last one decade with multiple industries and gradual rise in the population size. The other risk factors associated includes; social factors, social and cultural taboos, environmental factors, sedentary life style, genetic and risk factors. ${ }^{13}$

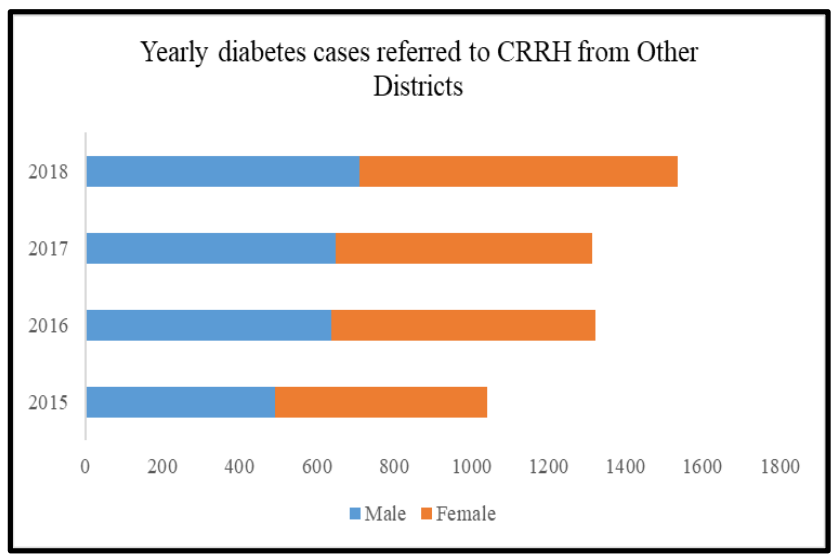

Figure 3. Diabetes cases referred to CRRH Diabetic clinic from other districts

This study found $5 \mathbf{2} \%$ of the diabetic patients were female. This is in consistence to the finding reported by an earlier study. 9 Obesity is a major risk factor for $\mathrm{T}_{2} \mathrm{DM}^{14,15}$ and it confers increased risk for $\mathrm{T}_{2} \mathrm{DM}$ through the mechanism of associated insulin resistance. The WHO-Bhutan factsheet presents $40 \%$ of Bhutanese women are either overweight or obese whereas $27 \%$ of men were reported to be either overweight or obese. ${ }^{16}$ A study conducted in eastern part of Bhutan among secondary school students reported a higher prevalence of obesity in adolescent female population. ${ }^{17}$ On the other hand, TiDM is significantly low in CRRH, only three cases of TiDM were recorded in last 5 years at CRRH.

Population ageing has set in Bhutan. ${ }^{18}$ The current study found that $59.51 \%$ of new cases of diabetes were $\geq 50$ years. Ageing society also plays a critical role in moderation of lifestyle related diseases. There was a stark increase in elderly population by $79.48 \%$ between 2005 and 2017. ${ }^{15}$ The increasing life expectancy will also contribute to predicted upsurge in regional diabetes rate. Diabetes and other NCDs can also lead to old age mental illness (WHO, 2012). Therefore, treating NCDs among the elderly population may be done within the purview of addressing mental health conditions.

The International Diabetes Federation (IDF) atlas projects the total number of diabetes cases in Bhutan to be over 41000 and national prevalence rate to be $7 \cdot 7 \%{ }^{13}$ However, the overall diabetes prevalence under the CRRH catchment area is found to be $2.91 \%$ with lowest at Chhudzom Gewog (1.01\%) and highest in Samtenling Gewog (3.18\%), as shown in figure 4. The annual detection rate is estimated to be $2.22 \%$ and $1.45 \%$ in 2015 and 2018 respectively. This calls for more proactive public health awareness and screening campaign to clear the estimated detection gap.

Although the anecdotal evidences say that many patients do not visit the DM clinics regularly and there is considerable LTFU and the earlier study by Zam et al., (2015) $)^{9}$ found $21 \%$ of the diabetes patients were LTFU in Bhutan but the current analysis found only $3.96 \%, 5.0 \%, 6.47 \%$ and $5.85 \%$ of new diabetes cases were LTFU from 2015 to 2018 respectively. This is comparatively lower and the decrease could be attributed to proper health education to patients, good laboratory testing facility and dedicated clinic for diabetes patients operating 5 days a week. Moreover, diabetic patients not reporting to clinic for more than four months are being followed up telephonically.

Diabetes along with other co-morbidities such as high blood pressure is a major factor contributing to the occurrence of chronic kidney diseases. ${ }^{5}$ Bhutan still refers chronic kidney disease patients abroad for treatment and the number keeps increasing annually by $15 \% .5$ Though Bhutan will be soon graduating from low to middle income country, the rising cases of diabetes and other NCDs poses a threat to the sustainability of our free health care system. Maintaining a free health care system is enshrined in the Constitution of the Kingdom of Bhutan. ${ }^{19}$

Limitations: The study was not able to extract data on conversion rate from pre-diabetes to diabetes. The data 


\section{Diabetes Prevelance}

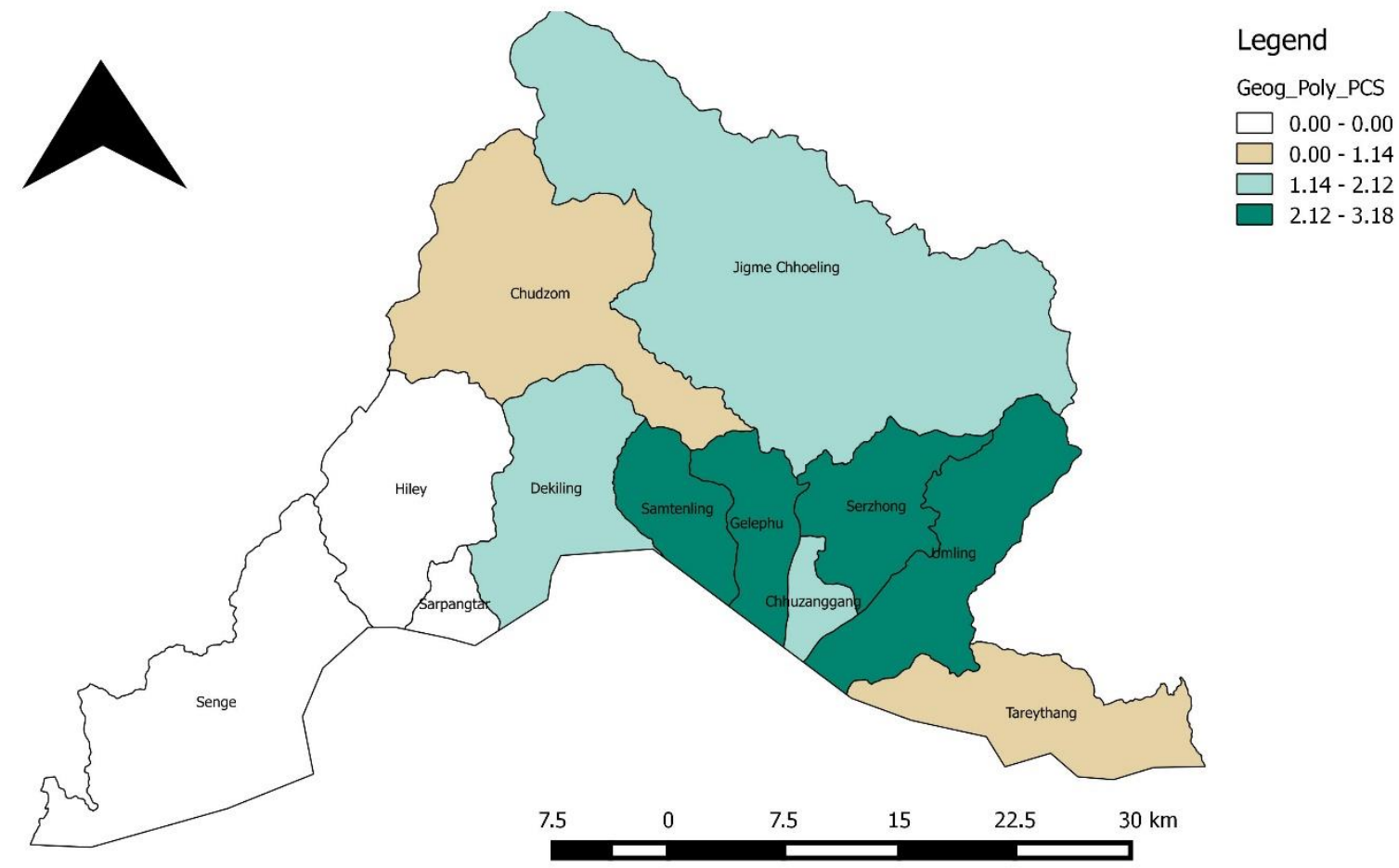

Figure 4. Prevalence of Diabetes at Gewogs under Gelephu CRRH

(Note: Sengye, Hiley, Sarpangtar Gewog not a catchment area under Gelephu, CRRH)

on LTFU for 2014 was unavailable.

\section{CONCLUSION}

The ageing population and change in lifestyle has contributed to rise in the number of $\mathrm{T}_{2} \mathrm{DM}$ cases in Bhutan. CRRH recorded 1590 cases in 2018 with an increase of two-fold within the span of five years. The overall diabetes prevalence under the CRRH catchment area is found to be $2.91 \%$ with lowest at Chhudzom Gewog (1.01\%) and highest in Samtenling Gewog (3.18\%). The study found that only $3.96 \%, 5.0 \%, 6.47 \%$ and $5.85 \%$ of new diabetes cases were lost to follow up from 2015 to 2018 respectively. The study recommends strengthening community awareness and screening programs for early case detection and management.

\section{ACKNOWLEDGEMENT}

We are thankful to Medical Superintendent CRRH, Gelephu for support during data collection and verification. We are also thankful to $\mathrm{MoH}$ for permitting us to conduct this study.

\section{REFERENCES}

1. Inzucchi SE, Sherwin RS. Type 2 diabetes mellitus. Cecil Medicine 24th ed Philadelphia, Pa: Saunders Elsevier. 2011.

2. Kaveeshwar SA, Cornwall J. The current state of diabetes mellitus in India. The Australasian Medical Journal 2014;7(1):45-8.

3. Howdon D, Rice N. Health care expenditures, age, proximity to death and morbidity: Implications for an ageing population. Journal of Health Economics 2018;57:60-74.

4. Mokdad AH, Ford ES, Bowman BA, Dietz WH, 
Vinicor F, Bales VS, et al. Prevalence of obesity, diabetes, and obesity-related health risk factors, 2001. JAMA. 2003;289(1):76-9.

5. Dorji T, Yangchen P, Dorji C, Nidup T, Zam K. An approach to diabetes prevention and management: the Bhutan experience. WHO South-East Asia Journal of Public Health 2016;5(1):44-7.

6. The Growing Danger of Non-Communicable Diseases: Acting Now to Reverse Course. Washington DC: The World Bank; 2011.

7. Wild S, Roglic G, Green A, Sicree R, King H. Global prevalence of diabetes: estimates for the year 2000 and projections for 2030. Diabetes care. 2004;27(5):1047-53. https://doi.org/10.4103/2224-3151.206552

8. Palmer SC, Strippoli GF. Metformin as first-line treatment for type 2 diabetes. The Lancet. 2018;392(10142):120. https://doi.org/10.1016/So140-6736 (18) 31541-1

9. Zam K, Kumar AM, Achanta S, Bhat P, Naik B, Zangpo K, et al. A first country-wide review of Diabetes Mellitus care in Bhutan: time to do better. BMC Health Services Research 2015;15(1):389.

10. Dimeski G, Yow KS, Brown NN. What is the most suitable blood collection tube for glucose estimation? Annals of Clinical Biochemistry 2015;52(2):270-5.

11. American Diabetes Association. Diagnosis and Classification of Diabetes Mellitus. Diabetes Care. 2010 Jan; 33(Suppl 1): S62-S69.

12. Chhetri V, Yangchen K, Dawa C. Increasing Trend of Clinical Laboratory Testing at Gelephu Central Regional Referral Hospital, Bhutan. International Journal of Innovative Research in Medical Science
(IJIRMS) 2018;3(11):2265-9. https://doi.org/10.23958 /ijirms/volo3-i11/463

13. Ramachandran A, Snehalatha C, Ma RCW. Diabetes in south-east Asia: An update. Diabetes Research and Clinical Practice 2014;103(2):231-7.

14. Burke JP, Williams K, Gaskill SP, Hazuda HP, Haffner SM, Stern MP. Rapid rise in the incidence of type 2 diabetes from 1987 to 1996: results from the San Antonio Heart Study. Archives of Internal Medicine 1999;159(13):1450-6.

15. Centers for Disease Control and Prevention (CDC). Trends in the prevalence and incidence of self-reported diabetes mellitus--United States, 1980-1994. MMWR Morbidity and mortality weekly report. 1997;46(43):1014.

16. World Health Organization. National survey for noncommunicable disease risk factors and mental health using WHO STEPS approach in Bhutan-2014.

17. Norbu W, Wangdi U, Dorji D, Arthan D, Soonthornworasiri N, Maneekan P, et al. Obesity prevalence and contributing factors among adolescents in secondary schools in Pemagatshel district, Bhutan. International journal of adolescent medicine and health. 2017;31(1). https://doi.org/10.1515/ijamh-20160143.

18. Wangdi K, Jamtsho T. Risk factors for self-reported diabetes among Bhutanese adults: A nationally representative survey data analysis. PloS one. 2018;13(11):e0206034.

19. Adhikari D. Healthcare and happiness in the Kingdom of Bhutan. Singapore Medical Journal. 2016;57(3):107-9. https://doi.org/10.11622/smedj.201604 9. 